\title{
PELATIHAN MENGHADAPI BERITA PALSU DI ERA REVOLUSI INDUSTRI 4.0 DI KABUPATEN KUBU RAYA
}

\author{
Aunurrahman $^{1}$, Maliqul Hafis ${ }^{2}$, Sahrawi $^{3}$ \\ ${ }^{1,2,3}$ Program Studi Pendidikan Bahasa Inggris, Fakultas Pendidikan Bahasa dan Seni, \\ IKIP-PGRI Pontianak, Jalan Ampera No.88 Pontianak \\ 1e-mail: yarrha@gmail.com
}

\begin{abstract}
Abstrak
Pelatihan menghadapi berita palsu di era revolusi industri 4.0 ini bertujuan untuk membangun pengetahuan dan kemampuan dasar siswa dalam menghadapi berita palsu atau "hoax" yang sering kali menyebar secara daring dan dapat merugikan banyak orang. Pelatihan ini dilaksanakan di Pondok Pesantren Hidayatul Mubtadi-Ien di Kubu Raya yang diikuti oleh 28 siswa yang terdiri dari siswa kelas 8 (sebanyak 4 siswa), kelas 9 (sebanyak 15 siswa), dan kelas 10 (sebanyak 9 siswa). Siswa diberikan materi mengenai berita palsu seperti indikator elemen berita yang perlu diperhatikan, dampak dari berita palsu, dan cara mencegah penyebaran berita palsu. Selesai pelatihan diberikan, siswa diminta untuk mengisi kuesioner persepsi akhir. Respon para siswa menunjukkan adanya perkembangan pengetahuan akan indikator berita palsu yang sangat diperlukan mereka untuk mengenali berita palsu. Dengan mengenali indikator tersebut, para siswa paham apa yang akan mereka lakukan selanjutnya, seperti mengecek kebenaran berita tersebut dan tidak membagi berita tersebut apabila dianggap palsu ke media sosial ataupun layanan sosial daring yang bisa berdampak negatif bagi orang lain. Dapat disimpulkan bahwa pelatihan menghadapi berita palsu bermanfaat bagi siswa dalam mengenali berita palsu melalui indikator yang telah diajarkan dan tindakan apa yang perlu dilakukan seandainya mereka menemukan berita yang dibagi ke akun sosial media ataupun layanan sosial mereka.
\end{abstract}

Kata Kunci: Pelatihan, berita palsu, kabupaten Kubu Raya

\begin{abstract}
Training to encounter hoax news in the era of industrial revolution 4.0 aims to build knowledge and skills required by students in encountering hoax news that have been frequently shared online and harmed many people. The training was conducted at Hidayatul Mubtadi-Ien Islamic boarding school in Kubu Raya. 28 students consisted of students from class 8 (4 students), class 9 (15 students), and class 10 (9 students) participated in the training. Materials such as elements of hoax news, the harmful effects of hoax news, and steps for preventions are provided to the students. To complete the training, the students filled a questionnaire. The students' responses show that the students could develop their knowledge that is needed to identify hoax news. Using the knowledge of the elements of hoax news, the students understood that they should check the validity of the news and they should not share it to social medias or chatting applications if the news article is considered as a hoax news that could be harmful for others. In conclusion, the training to encounter hoax news provides benefits for students in identifying hoax news through the indicators that have been learned and in preventing the hoax news to be spread online.
\end{abstract}

Keywords: Training, hoax news, Kubu Raya regency 


\section{PENDAHULUAN}

Literasi merupakan kemampuan dasar yang sangat diperlukan untuk melakukan banyak hal. Salah satu kemampuan tersebut diantaranya adalah membaca dan menulis. Kemampuan literasi dasar ini memungkinkan seseorang untuk mendapatkan informasi dan menggunakan informasi tersebut untuk kebutuhan hidupnya atau kerjanya (UNESCO, 2010).

Bertepatan dengan era revolusi industri 4.0, literasi pun telah berkembang sedemikian rupa. Beberapa bentuk literasi yang disebut sebagai literasi baru diantaranya adalah literasi data, literasi teknologi, dan literasi manusia (Hamdan, 2018; Ibda, 2018; Okezone, 2018; Suwardana, 2018). Namun, tetap saja untuk mendapatkan literasi baru ini tidak dapat lepas dari kemampuan literasi dasar manusia yang sudah disebut sebelumnya, yaitu, membaca dan menulis.

Kenyataannya adalah, segala sesuatu yang baru di era revolusi industri 4.0 ini dikemas secara menarik. Tidak terlepas juga termasuk berita hoaks atau palsu yang sering menyebar secara daring. Berita hoaks adalah istilah yang digunakan di Indonesia yang berarti berita palsu. Berita hoaks atau berita palsu adalah berita yang dibuat tanpa bukti atau fakta yang mendukung berita tersebut dengan tujuan memberikan informasi palsu atau bohong (Constitutional Rights Foundation, 2017; Simons, 2018). Berita palsu ini cenderung mudah menyebar secara daring terutama di antar muka situs web dan media sosial (Aymanns, Foerster, \& Georg, 2017; Balmau dkk., 2018; Kim, Tabibian, Oh, Schölkopf, \& Gomez-Rodriguez, 2018; Kumar \& Shah, 2018; Shao dkk., 2018).

Lebih jauh, berita palsu cenderung membawa efek negatif secara psikologis bagi para pembacanya baik secara langsung maupun tidak langsung. Contohnya, berita palsu yang memaparkan kekerasan atau kecelakaan dapat menimbulkan rasa cemas, resah, dan takut. Contoh lain adalah apabila ada berita yang memaparkan hal-hal negatif tentang suatu golongan, perusahaan, institusi cenderung akan mudah dipercayai oleh orang-orang yang tidak menyukai golongan, perusahaan, dan institusi yang dimaksud (Widiyarti, 2018).

Untuk menghadapi berita palsu ini, siswa-siswi di Pondok Pesantren Hidayatul Mubtadi-Ien di Kubu Raya, Kalimantan Barat harus diberi pelatihan 
menghadapi berita palsu di era revolusi industri 4.0 ini. Dengan pelatihan ini, diharapkan siswa-siswi tersebut dapat lebih bijaksana dalam membaca dan mencari informasi dan tidak mudah terpengaruh oleh berita palsu yang bertaburan secara daring karena berita hoaks cenderung memiliki sifat yang merusak (lihat Bovet \& Makse, 2019; Kompas Cyber Media, 2017; McGonagle, 2017; Pangrazio, 2018; Scheufele \& Krause, 2019).

Materi yang telah disampaikan di dalam pelatihan menghadapi berita palsu di era revolusi industri 4.0 ini diantaranya adalah mengidentifikasi berita hoaks atau berita palsu. Ada beberapa strategi yang dapat digunakan untuk mengidentifikasi berita hoaks atau berita palsu, diantaranya adalah: (1) Memerhatikan judul berita; (2) Memerhatikan alamat situs; (3) Memeriksa validas berita; (4) Memeriksa keaslian foto atau dokumen yang digunakan; dan (5) Berpartisipasi dalam grup diskusi anti-hoaks (Nugroho, 2017).

Strategi-strategi ini diajarkan kepada para siswa-siswi di Pondok Pesantren Hidayatul Mubtadi-Ien di Kubu Raya untuk membantu mereka mengidentifikasi berita palsu terutama di era revolusi industri 4.0 yang juga dikenal dengan era literasi digital ini. Selain itu, para siswa juga diajarkan mengenai bagaimana cara menghentikan penyebaran berita hoaks atau palsu yang merugikan banyak orang. Dua hal yang perlu diketahui untuk mencegah penyebaran berita palsu adalah: (1) Jangan membagi sebuah teks berita ke layanan media sosial ataupun layanan obrolan daring tanpa membaca dan memvalidasi konten teks berita tersebut secara menyeluruh; (2) Jangan berlaku subyektif terhadap suatu informasi yang anda temukan di sebuah teks berita apalagi teks berita yang mendukung pandangan atau pendapat anda tanpa memeriksa kebenaran berita tersebut (Washington Post, 2017)

\section{METODE}

Kegiatan pengabdian kepada masyarakat (PKM) ini berupa pelatihan menghadapi berita palsu di era revolusi industri 4.0 yang diadakan di Pondok Pesantren Hidayatul Mubtadi-Ien yang berlokasi di Jalan Parit Masigi, Sul Ambawang Kuala, Sungai Ambawang, Kabupaten Kubu Raya, Kalimantan Barat 
pada tahun akademik 2018/2019. Berikut adalah peta lokasi kegiatan pelatihan menghadapi berita palsu dilaksanakan.

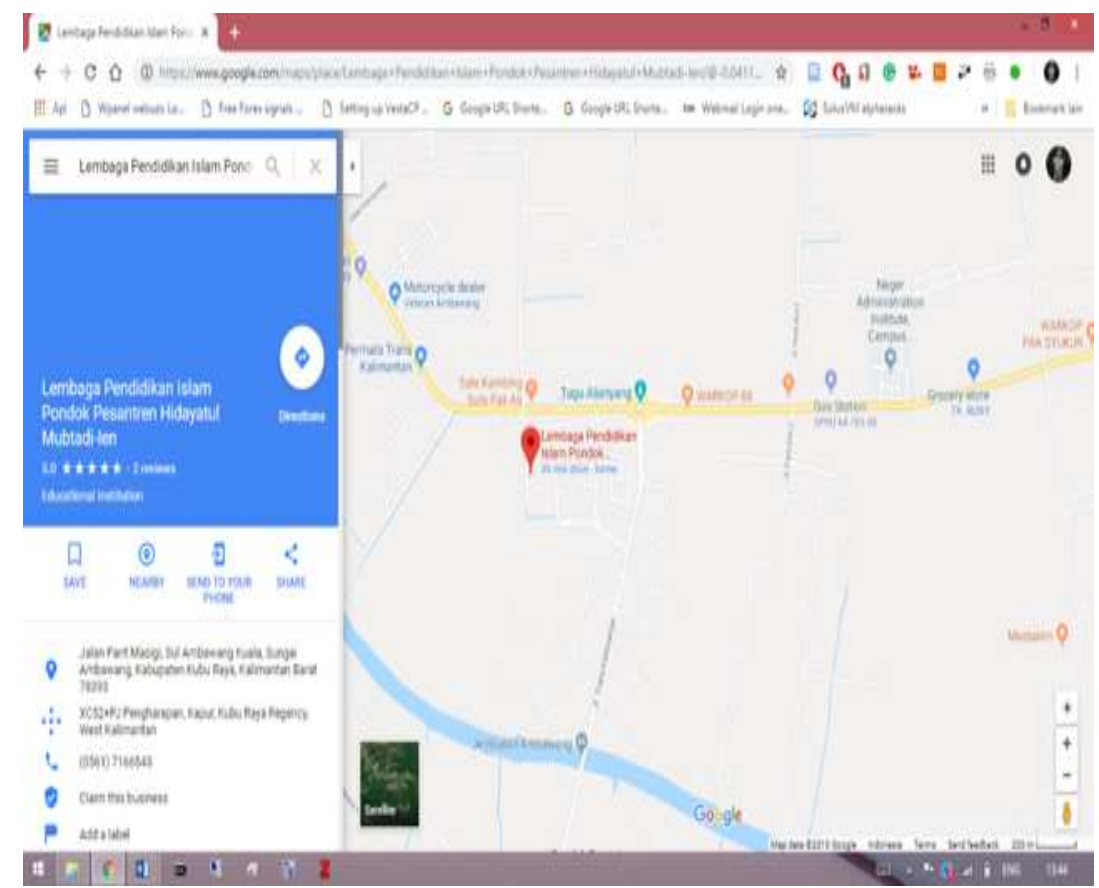

Gambar 1. Peta Lokasi Kegiatan PKM

Para partisipan yang terlibat di dalam pelatihan menghadapi berita palsu ini adalah siswa-siswi di lingkungan pondok pesantren tersebut. Jumlah seluruh siswa yang hadir adalah 28 siswa yang terdiri dari 9 siswa kelas 10, 15 siswa kelas 9, dan 4 siswa kelas 8. Pengumpulan data yang dipakai dalam kegiatan PKM ini adalah (1) kuesioner persepsi dan (2) catatan lapangan. Deskripsi instrumen yang digunakan di dalam pengumpulan data yaitu kuesioner persepsi dan catatan lapangan. Kuesioner persepsi, digunakan untuk mengetahui persepsi siswa akan berita palsu atau berita hoaks. Kuesioner dikerjakan siswa secara individu yang diberikan di awal dan di akhir materi pembelajaran. Catatan lapangan dilakukan dengan mendokumentasikan proses pembelajaran baik dari aktivitas guru maupun siswa serta lingkungan atau kondisi pembelajaran dan foto kegiatan selama proses belajar mengajar baik sebelum maupun ketika dilaksanakan tindakan.

Selesai dengan pengumpulan data, pelaksana kegiatan PKM ini menggunakan teknik analisis data deskriptif kualitatif untuk menganalisis data yang dikumpulkan menggunakan instrumen kuesioner persepsi dan catatan 
lapangan. Tujuan analisis ini adalah untuk membuat gambaran secara sistematis data yang faktual dan akurat mengenai fakta-fakta serta hubungan antar fenomena yang diselidiki atau diteliti. Data yang diperoleh dari kegiatan PKM ini berupa data catatan lapangan yang dilakukan selama proses kegiatan PKM berlangsung dan persepsi siswa akan berita palsu di awal dan akhir kegiatan. Analisis deskriptif adalah analisis yang menggunakan suatu data yang akan dibuat sendiri maupun dibuat secara berkelompok (Arikunto \& Suhardjono, Supardi, 2009, hlm. 27). Berikut adalah peta kajian analisis data berdasarkan masing-masing target kegiatan.

Tabel 1. Peta kajian analisis data

\begin{tabular}{|c|c|}
\hline Target & Analisis data \\
\hline $\begin{array}{l}\text { 1. Membangun pengetahuan } \\
\text { dan kemampuan dasar } \\
\text { menghadapi berita hoaks. }\end{array}$ & $\begin{array}{l}\text { Analisis data dilakukan berdasarkan hasil } \\
\text { kegiatan siswa dalam mengerjakan kuesioner } \\
\text { persepsi mengenai berita hoaks dan } \\
\text { berdasarkan catatan lapangan terhadap siswa, } \\
\text { guru dan/atau } \\
\text { kepala sekolah selama kegiatan PKM } \\
\text { berlangsung }\end{array}$ \\
\hline
\end{tabular}

\section{HASIL DAN PEMBAHASAN}

Pelaksanaan kegiatan pelatihan ini diharapkan dapat membantu sekolah dan guru dalam mempersiapkan siswa-siswi dalam menghadapi berita palsu dan penyebarannya. Kedatangan tim PKM disambut dengan baik oleh kepala sekolah beserta pemilik pondok pesantren. Pelatihan menghadapi berita palsu dilaksanakan kepada 28 siswa yang terdiri dari 9 siswa kelas 10, 15 siswa kelas 9, dan 4 siswa kelas 8 yang telah berkumpul di ruangan yang disiapkan oleh pihak sekolah. Pihak sekolah juga dengan baik telah mempersiapkan perlengkapan audio untuk mendukung kegiatan ini. Sebelum memulai pelatihan, tim PKM memberikan salinan materi pelatihan. Kuesioner persepsi awal juga dibagikan kepada para siswa untuk mengetahui pengetahuan dasar mereka akan berita hoaks atau berita palsu. Contoh respon siswa terhadap kuesioner persepsi awal diantaranya adalah: 
Berita hoaks adalah berita yang belum tentu benar-benar terjadi (Mamad) berita yang tidak benar-benar terjadi dan berita yang dibuat-buat orang agar menjadi heboh. (Permata)

Respon Mamad dan Permata (nama alias) terhadap kuesioner persepsi awal menunjukkan bahwa para siswa mengetahui apa itu berita hoaks atau berita palsu. Sayangnya, kebanyakan respon-respon yang diberikan oleh siswa berdasarkan dari salinan materi yang telah diberikan sebelumnya. Para siswa juga mengetahui bahwa berita hoaks bisa memiliki dampak negatif. Contoh respon siswa diantaranya adalah:

ia karena orang lain bisa terkena dampaknya. (Senin)

iya, karna berita hoaks adalah berita yang tidak benar. (Amin)

Respon Senin dan Amin menunjukkan bahwa para siswa mengetahui bahwa berita hoaks atau berita palsu bisa membawa dampak negatif bagi para pembacanya. Hal ini juga didukung oleh penelitian-penelitian yang menunjukkan bahwa berita palsu membawa akibat yang buruk bagi manusia dan komunitasnya (lihat Bovet \& Makse, 2019; Scheufele \& Krause, 2019) yang bisa saja berujung pada tindakan-tindakan negatif dan bahkan kriminal (Dewi, 2018; Tribun News, 2019; Tribun Pontianak, 2019).

Namun, mereka belum dapat menjabarkan dampak negatifnya secara mandiri kecuali dengan melihat dari salinan materi yang telah diberikan juga pada saat distribusi kuesioner persepsi awal dilakukan. Siswa juga diberikan pertanyaan mengenai apa yang mereka lakukan ketika mereka menemukan teks berita di layanan media sosial ataupun obrolan daring. Contoh respon siswa diantaranya adalah:

Tidak didulikan karna takut dibohongi seharusnya berita hoaks ini tidak boleh diterima karena merusak semua masyarakat. (Nana)

Ya tidak tau. (Mira, Permata, Lala, dan Lulu) 
Respon Mira, Permata, Lala, dan Lulu menunjukkan bahwa mereka tidak mengetahui apa yang harus yang dilakukan ketika mereka menemukan teks berita yang bertaburan di layanan media sosial dan obrolan daring. Walaupun demikian, Nana memberikan jawaban mandiri yang cukup jelas, yaitu untuk tidak dipedulikan karena sifatnya yang merugikan. Sayangnya lagi, respon-respon siswa yang lain itu berdasarkan salinan materi yang telah diberikan sebelumnya. Tetap saja, hal ini menunjukkan bahwa siswa-siswi yang mengikuti pelatihan ini memiki rasa ingin tahu terhadap isu berita palsu dimana mereka mau membaca dan memahami salinan materi pelatihan yang diberikan walaupun belum diminta untuk membacanya.

Selesai mengisi kuesioner persepsi awal, sesi pelatihan dimulai dengan tim PKM menyampaikan materi tentang definisi dan struktur skematis berita. Teks berita merupakan materi yang juga diajarkan kepada siswa SMP. Selanjutnya, tim PKM menyampaikan materi tentang definisi, dampak, dan strategi menghadapi berita palsu. Contoh teks berita palsu juga diberikan. Di tahapan ini, tim PKM menunjukkan elemen-elemen teks berita yang bisa menjadi indikator berita palsu seperti yang telah disebutkan sebelumnya dalam strategi menghadapi berita hoaks.

Selesai dengan contoh teks palsu, tim PKM melanjutkan pelatihan dengan memberikan 2 studi kasus. Pertama, siswa dibagi menjadi beberapa kelompok. Setelah pembagian kelompok, siswa dalam kelompok diberi tugas untuk mengidentifikasi apakah teks yang diberikan termasuk kedalam berita palsu atau fakta. Peran para dosen disini adalah membantu dan membimbing siswa dalam mengidentifikasi elemen-elemen berita palsu. Tujuan dari bimbingan ini adalah mempersiapkan siswa agar dapat melakukan identifikasi berita palsu tersebut secara mandiri (lihat Aunurrahman, Hamied, \& Emilia, 2017a, 2017b). Strategi yang diberikan tidaklah sia-sia. Ketika tim PKM memonitor kerja siswa, siswasiswi tersebut dapat mengidentifikasi apakah teks yang diberikan termasuk fakta atau berita hoaks.

Sebagai contoh, tim PKM menanyakan kepada seorang siswi mengenai perkembangan tugas yang dikerjakan. Siswi tersebut, sebut saja Siska, memberikan jawaban yang menarik. Dia menemukan bahwa teks yang dibacanya itu merupakan 
teks berita palsu. Hal ini dilihat dari informasi eksplisit yang menurutnya salah. Disini, siswa menggunakan pengetahuan dasar dan pengetahuan yang didapatinya selama pelatihan dalam mengenali informasi palsu yang tercantum dari sebuah teks. Tentu saja, pendidikan yang didapatkan para siswa selama di pondok pesantren juga memberikan bekal dasar bagi siswa dalam mengenali konten palsu terutama yang berhubungan dengan topik pendidikan agama.

Selesai dengan dua studi kasus yang diberikan kepada siswa, tim PKM mendistribusikan kuesioner persepsi akhir sebagai evaluasi akhir pelatihan. Respon siswa terhadap kuesioner persepsi akhir menunjukkan hasil yang baik. Contohnya, pemahaman siswa akan berita hoaks atau palsu menunjukkan adanya perkembangan pengetahuan akan berita palsu. Contoh respon siswa diantaranya adalah:

Kita dapat mengerti hoak dan yang fakta dan kita bisa tau mana berita asli dan yang bukan. (Mira, Lala, Lulu, Permata)

Bisa lebih memahami dan bisa menghadapi jikalau ada berita hoaks. Sudah bisa dan mengenal apa itu hoaks dan bisa mencari mana yang benar dan yang salah. (Selasa)

Kita harus berhati hati jangan terlalu percaya tentang berita itu hoaks atau fakta, karna jika kita cepat mempercayainya kita akan gampang tidak percaya dengan yang lainnya. (Uma)

Ternyata berita hoaks juga hampir sama dengan berita fakta. Sulit untuk kita yang belum paham mengetahui itu hoaks atau fakta. (Desember)

Respon siswa diatas menunjukkan bahwa siswa paham bahwa berita palsu merupakan berita yang tidak sesuai fakta. Mereka juga mengetahui bahwa ada dampak negatif apabila berita hoaks beredar di masyarakat dimana muncul prasangka negatif yang bisa merusak kepercayaan orang terhadap orang lain. Satu hal lagi yang menarik adalah mereka mengklaim sudah dapat mengidentifikasi berita palsu dan fakta dimana bisa saja sulit bagi orang yang tidak memiliki pengetahuan dasar akan strategi mengidentifikasi berita palsu. 
Lebih jauh, siswa juga dapat mengutarakan tindakan yang akan mereka lakukan apabila menemukan teks berita yang dibagikan secara daring di media sosial dan layanan obrolan daring. Contoh respon siswa diantaranya adalah sebagai berikut.

Kita harus mengeceknya terlebih dahulu. (Amat, Aman, Rosi)

Saya akan ambil lalu saya memahami judul berita, alamat situs, dan saya mencari penerbit (penulis). (Selasa)

Kita harus hapus berita yang disebutkan / kita tidak boleh membagikan berita tersebut. (Ryan)

Respon siswa-siswa ini menunjukkan bahwa mereka memiliki sikap hati-hati atau preventif ketika mereka menemukan sebuah teks berita yang dibagikan via media sosial dan layanan obrolan daring dimana mereka akan memeriksa teks berita tersebut terlebih dahulu. Lebih jauh, Selasa memberikan saran dari strategi yang telah diterimanya dari pelatihan, yaitu dengan memahami judul, situs, dan penulis yang bertanggungjawab akan berita teks tersebut.

Akan menjadi bahaya apabila sebuah teks berita tanpa keterangan penulis atau penerbit yang jelas dapat dipercayai oleh orang dengan mudah. Ryan memberikan saran yaitu dengan menghapus dan tidak membagikan berita tersebut. Hal ini patut menjadi perhatian karena dengan tidak membagikan tautan berita palsu kepada kontak atau kawan-kawan akan membantu memutuskan rantai komunikasi dari teks berita palsu tersebut.

Bagian terakhir dari kuesioner adalah saran dan kritik siswa terhadap pelatihan menghadapi berita palsu. Beberapa saran dari siswa diantaranya adalah sebagai berikut.

Saya merasa senang karena bisa tau berita hoaks itu apa. (Aim)

Sebab ada pelatihan anti hoaks kita tidak menjadi kericuhan / kesalahpahaman. (Rosi)

Kurang waktu pelatihannya. Penyampaiannya baik dan bermanfaat. (Desember, Mulia) 
Respon siswa menunjukkan bahwa ada perkembangan persepsi dan pengetahuan yang berguna untuk identifikasi berita hoaks dimana siswa mengklaim mengetahui apa itu berita palsu atau berita hoaks beserta dampaknya. Temuan ini menunjukkan bahwa pelatihan menghadapi berita palsu era revolusi industri perlu dilakukan untuk membantu siswa-siswi di pondok pesantren tersebut dalam menghadapi berita palsu yang cenderung memiliki efek merusak dengan memberikan pengetahuan dan kemampuan dasar yang diperlukan untuk mengidentifikasi berita palsu. Namun, kegiatan PKM ini tidak lepas dari kekurangan. Siswa seperti Desember dan Mulia menyebutkan bahwa durasi kegiatan ini kurang. Tetap saja, mereka juga menganggap bahwa pelatihan yang diberikan bermanfaat bagi mereka.

\section{SIMPULAN}

Kegiatan pengabdian kepada masyarakat berupa pelatihan menghadapi berita palsu ini dilaksanakan kepada siswa-siswa Pondok Pesantren Hidayatul MubtadiIen untuk membantu siswa-siswi dalam mengidentifikasi berita palsu karena berita palsu cenderung memiliki karakteristik yang merugikan orang lain beserta komunitasnya. Respon siswa terhadap kuesioner persepsi awal sebelum pelatihan menunjukkan bahwa siswa memiliki pemahaman yang minim akan berita palsu. Mereka juga bingung tentang tindakan apa yang perlu mereka lakukan ketika mereka menemukannya.

Setelah dilakukannya pelatihan menghadapi berita hoaks, siswa memiliki pemahaman dasar akan berita palsu dan mengetahui apa yang harus mereka lakukan seandainya mereka menemukan berita palsu baik di layanan media sosial maupun obrolan daring. Temuan ini juga didukung dari temuan catatan lapangan selama pelatihan berlangsung dimana seorang siswi bisa menemukan konten yang tidak benar dari sebuah teks berita. Hal ini tentu saja dapat terjadi dikarenakan siswa memiliki pengetahuan dan kemampuan dasar yang diperlukan untuk mengidentifikasi berita palsu. Selain itu, pengetahuan siswa selama bersekolah di Pondok Pesantren Hidayatul Mubtadi-Ien sangat berguna untuk siswa-siswi dalam mengenali berita palsu terutama yang terkait dengan pendidikan agama. 
Siswa-siswi yang mengikuti pelatihan ini memberikan saran agar durasi pelatihan menghadapi berita palsu ini ditambah. Selain itu, siswa menyebutkan bahwa pelatihan menghadapi berita palsu sangat berguna. Oleh karena itu, pelatihan seperti ini perlu untuk diadakan ke sekolah-sekolah karena perkembangan teknologi yang terjadi saat ini bisa saja membawa dampak negatif bagi para siswa apabila tidak diberi bekal yang cukup terutama untuk menghadapi berita palsu yang dengan mudah menyebar di layanan media sosial dan obrolan daring.

\section{UCAPAN TERIMA KASIH}

Tim Pengabdian Kepada Masyarakat dari Program Studi Pendidikan Bahasa Inggris IKIP-PGRI Pontianak mengucapkan terima kasih kepada pemilik Pondok Pesantren Hidayatul Mubtadi-Ien, yaitu Bapak Yusri dan Kepala Sekolah SMK Hidayatul Mubtadi-Ien, yaitu Bapak Toha Purwanto, S.Pd. I beserta guru di lingkungan Pondok Pesantren Hidayatul Mubtadi-Ien yang telah memberikan kami izin, waktu, dan tempat untuk melaksanakan pengabdian kepada masyarakat berupa pelatihan menghadapi berita palsu di era revolusi industri 4.0. Kami juga berterima kasih kepada siswa-siswi yang telah berpartisipasi dalam kegiatan pelatihan ini.

\section{DAFTAR PUSTAKA}

Arikunto, S., \& Suhardjono, Supardi. (2009). Penelitian tindakan kelas. Jakarta: Bumi Aksara.

Aunurrahman, Hamied, F. A., \& Emilia, E. (2017a). A joint construction practice in an academic writing course in an Indonesian university context. Celt ( $A$ Journal of Culture, English Language Teaching \& Literature), 17(1), 2744. https://doi.org/10.24167/celt.v17i1.1137

Aunurrahman, Hamied, F. A., \& Emilia, E. (2017b, April). Modeling academic writing for university students. Dipresentasikan pada Ninth International Conference on Applied Linguistics (CONAPLIN 9). Diambil dari http://atlantis-press.com/php/paper-details.php?id=25874116

Aymanns, C., Foerster, J., \& Georg, C.-P. (2017). Fake news in social networks (SSRN Scholarly Paper No. ID 3023320). Diambil dari Social Science Research Network website: https://papers.ssrn.com/abstract=3023320

Balmau, O., Guerraoui, R., Kermarrec, A.-M., Maurer, A., Pavlovic, M., \& Zwaenepoel, W. (2018). Limiting the spread of fake news on social media 
platforms by evaluating users' trustworthiness. arXiv:1808.09922 [cs]. Diambil dari http://arxiv.org/abs/1808.09922

Bovet, A., \& Makse, H. A. (2019). Influence of fake news in Twitter during the 2016 US presidential election. Nature Communications, 10(1), 7. https://doi.org/10.1038/s41467-018-07761-2

Constitutional Rights Foundation. (2017). Understanding fake news.

Dewi, K. S. (2018, Mei 29). Hoax bom di pesawat Lion Air Pontianak lukai 8 penumpang panik. liputan6.com. Diambil dari https://www.liputan6.com/news/read/3542457/hoax-bom-di-pesawat-lionair-pontianak-lukai-8-penumpang-panik

Hamdan, H. (2018). Industri 4.0: Pengaruh revolusi industri pada kewirausahaan demi kemandirian ekonomi. Jurnal Nusantara Aplikasi Manajemen Bisnis, 3(2), 1-8. https://doi.org/10.29407/nusamba.v3i2.12142

Ibda, H. (2018). Penguatan literasi baru pada guru Madrasah Ibtidaiyah dalam menjawab tantangan era revolusi industri 4.0. JRTIE: Journal of Research and Thought on Islamic Education, 1(1), 1-21.

Kim, J., Tabibian, B., Oh, A., Schölkopf, B., \& Gomez-Rodriguez, M. (2018). Leveraging the crowd to detect and reduce the spread of fake news and misinformation. Proceedings of the Eleventh ACM International Conference on Web Search and Data Mining, 324-332. https://doi.org/10.1145/3159652.3159734

Kompas Cyber Media. (2017, November 7). Cara cerdas mencegah penyebaran "Hoax" di media sosial. KOMPAS.com. Diambil dari https://nasional.kompas.com/read/2017/11/07/08020091/cara-cerdasmencegah-penyebaran-hoax-di-media-sosial

Kumar, S., \& Shah, N. (2018). False information on web and social media: A survey. arXiv:1804.08559 [cs], 1(1), 1-35.

McGonagle, T. (2017). "Fake news": False fears or real concerns? Netherlands Quarterly of Human Rights, 35(4), 203-209. https://doi.org/10.1177/0924051917738685

Okezone. (2018, September 26). Revolusi 4.0, mahasiswa dituntut pahami literasi baru. https://news.okezone.com/. Diambil dari https://news.okezone.com/read/2018/09/26/65/1955836/revolusi-4-0mahasiswa-dituntut-pahami-literasi-baru

Pangrazio, L. (2018). What's new about 'fake news'? Critical digital literacies in an era of fake news, post-truth and clickbait. Páginas de Educación, 11(1), 6-22. https://doi.org/10.22235/pe.v11i1.1551

Scheufele, D. A., \& Krause, N. M. (2019). Science audiences, misinformation, and fake news. Proceedings of the National Academy of Sciences, 116(16), 7662-7669. https://doi.org/10.1073/pnas.1805871115

Shao, C., Ciampaglia, G. L., Varol, O., Yang, K.-C., Flammini, A., \& Menczer, F. (2018). The spread of low-credibility content by social bots. Nature Communications, 9(1), 4787. https://doi.org/10.1038/s41467-018-06930-7

Simons, G. (2018). Fake news: As the problem or a symptom of a deeper problem? Образ. Diambil dari http://urn.kb.se/resolve?urn=urn:nbn:se:uu:diva-341503 
Suwardana, H. (2018). Revolusi industri 4. 0 berbasis revolusi mental. JATI UNIK: Jurnal Ilmiah Teknik dan Manajemen Industri, 1(2), 102-110. https://doi.org/10.30737/jatiunik.v1i2.117

Tribun News. (2019, Juli 1). Buat dan sebarkan 2.542 konten hoaks, warga Pontianak ditangkap Mabes Polri. Tribunnews.com. Diambil dari https://www.tribunnews.com/regional/2019/07/01/buat-dan-sebarkan-2542konten-hoaks-warga-pontianak-ditangkap-mabes-polri

Tribun Pontianak. (2019, Juli 5). Sebar berita hoax tentang Kapolri, pria asal Desa Kapur ini minta maaf. Tribun Pontianak. Diambil dari https://pontianak.tribunnews.com/2019/07/05/sebar-berita-hoax-tentangkapolri-pria-asal-desa-kapur-ini-minta-maaf

UNESCO. (2010). Why is literacy important? Diambil 20 September 2014, dari http://www.unesco.org/en/education-ar/themes/learning-throughoutlife/literacy/literacy-important/

Widiyarti, Y. (2018, Oktober 30). Kejamnya dampak hoax buat sisi psikologi manusia. Diambil 13 Februari 2019, dari Tempo website: https://cantik.tempo.co/read/1141397/kejamnya-dampak-hoax-buat-sisipsikologi-manusia 